\title{
Logistic performance assessment systems: structuring, challenges and development opportunities
}

Lucas de Oliveira Santos ${ }^{1}$, Denilson Ricardo de Lucena Nunes ${ }^{1}$, André Cristiano Silva Melo², Mariana Pereira Carneiro', Vitor William Batista Martins ${ }^{2}$

${ }^{1}$ University of Pará, Castanhal, PA, Brazil.

${ }^{2}$ University of Pará, Belém, PA, Brazil.

How to cite: Santos, L.O., Nunes, D.R.L., Melo, A.C.S. et al. (2020), "Logistic performance assessment systems: structuring, challenges and development opportunities", Brazilian Journal of Operations \& Production Management, Vol. 17, No. 3, e20201027. https://doi.org/10.14488/BJOPM.2020.039

\section{ABSTRACT}

Goal: The purpose of this article is to encourage discussion on the basic structuring of a logistics performance assessment system, as well as the challenges and opportunities identified in the development and implementation of new proposals.

Design / Methodology / Approach: A systematic literature review was adopted as a research strategy, based on a protocol adapted to the theme of this research. The bases searched were Scopus, Web of Science, Scielo and Science Direct.

Results: It was possible to identify a basic structure for the elaboration of a logistic performance evaluation system. In addition, a number of opportunities for developing the theme were observed, as well as the respective challenges to be overcome.

Limitations of the investigation: One of the limitations found was that the databases chosen did not always have articles available in their entirety, five of them were not available.

Practical implications: It is believed that this research can serve as a reference for researchers who are interested in proposing performance evaluation systems in the context of logistics, contributing to an initial understanding of its structure and highlighting the possible implementation challenges.

Originality / Value: According to the bases surveyed, this is the first survey that sought to identify the structure of the logistic performance assessment systems with a focus on business logistics.

Keywords: Logistic Performance; logistic performance indicators; performance evaluation.

\section{INTRODUCTION}

One of the objectives of logistics is to guarantee the efficiency and effectiveness of production processes from the origin to the final customer, paying attention to the quality required by the customer, ensuring the reliability of information and the flexibility to meet their needs (Domingues et al., 2015). The activities that converge towards the objectives of logistics are, according to Silva et al. (2015), from storage, handling, consolidation and deconsolidation (picking), as well as production scheduling.

Increasingly fierce competition, according to Kucukaltan et al. (2016), this has forced logistics companies to evaluate their performance using more effective measurement models, in order to be more competitive in the market. In addition, Domingues et al. (2015) highlight that the current competitive environment requires an imminent need to obtain control of

Financial support: This research was funded by Universidade do Estado do Pará - UEPA — Brazil, grant number 626/18.

Conflict of interest: The authors have no conflict of interest to declare.

Corresponding author: denilson.lucena@ibest.com.br

Received: 2 July 2020

Accepted: 29 July 2020

Guest Editors: Fernando Oliveira de Araujo and Chrystyane Abreu 
logistical costs, and the use of performance measurement has proven to be a great tool in achieving these objectives.

Fundação Dom Cabral (2018), points to an increase in logistics costs in Brazil of about 15.5 billion companies in the period from 2015 to 2017, which represents $12.37 \%$ of the revenue of these companies. For comparison purposes, according to the Instituto de Logística e Supply Chain (2019), logistics costs in Brazil are equivalent to $12.2 \%$ of GDP, against $7.8 \%$ in the United States. Higher investment does not necessarily mean greater efficiency, because according to the World Bank Group (2018), Brazil is in 56th position in logistics performance from a list of 160 countries. Thus, it becomes imperative to implement control systems and management of logistical systems. Melnyk et al. (2014) also emphasize the importance of performance evaluation as a facilitator of control and effective correction, informing the level of current performance and comparing it with the level of expected performance.

Despite the importance of performance evaluation, for Otley (2008), until then, there was not necessarily a universal configuration of performance measures, which are appropriate for all organizations and in all circumstances, but that these measures must be developed for specific contexts. Also according to this author, there are four main dimensions that performance measures are developed: financial, customer, business process, and innovation and learning. Following the line that performance evaluation should be diversified, FrancoSantos et al. (2012) and Melnyk et al. (2014) point out the need to evaluate performance in different contexts within organizations, which includes logistics.

According to the literature, performance evaluation uses indicators for its effectiveness. In this research, the same definition of indicator used by Neely et al. (2008), who defined performance indicators as a set of metrics used to quantify the efficiency and effectiveness of an action. Some of the well-known classic authors in the field of logistics (Ballou, 2006; Bowersox et al., 2014; Chopra and Meindl, 2016; Slack et al., 2015) present the assessment of logistics performance in comprehensive terms, without describing the operationalization of this process; without reference to specific indicators, for each of the dimensions involved in logistics; as well as the alignment of this assessment with the organization's strategy. In addition, they do not present well-defined metrics for their realization.

Therefore, this research aimed to understand how logistic performance measurement systems have been addressed in scientific articles, both from the point of view of structuring these systems and from the point of view of application, validation and results obtained. For that, a methodology similar to that applied in Reis et al. (2017), where a systematic literature review was used to identify the main aspects in the design and implementation of distribution centers, in this research the basic difference is in the focus on logistics performance.

\section{BUSINESS LOGISTICS AND PERFORMANCE EVALUATION}

Ballou (2006) and Bowersox and Closs (2007) bring the definition adopted by the Council of Logistics Management (CLM) of 1991, current Council of Supply Chain Management Professionals (CSCMP), which first changed the term "physical distribution management" to " logistics ", a term currently used. Then he presented the logistics as:

[...] the process of planning and implementing and efficient and effective control of the flow and storage of goods, services and related information from the point of origin to the point of consumption, in order to meet the needs of customers.

Council of Logistics Management (1998) also highlights the goal of logistics, ensuring that the right product, in the right quality, in a satisfactory condition, is delivered to the right customer, in the required place, at the right time and at an appropriate cost. Another definition of logistics is given by Slack et al. (2015) that calls logistics as the need to provide the movement of raw materials, as well as finished products to their destinations. In addition to organizing protection, storage and stock control. 
Logistics are responsible for managing information on customer demand, controlling orders, as well as tracking deliveries and corresponding payments, despite being performed by professionals from other areas of the organization (Arbache et al., 2011). This occurs due to the integration of different areas, because according to Bowersox and Closs (2007), logistics involves the integration of five large areas: information, transport, stock, storage, handling of materials and packaging.

The view of activity is explored by Ballou (2006), who presents a logistical system separated into main activities and support activities. The main activities are: Customer Service, Transportation, Inventory Management and Information Flow. In this context, the support activities are: Warehousing, Material Handling, Purchasing, Packaging Design, Cooperation with Production and Maintenance of Information. Slack et al. (2015) also consider logistics as interrelated activities: transport, storage, storage, material handling, security and order processing.

Both the view of activities and the understanding of areas of activity converge towards the objective of achieving adequate service levels for customers, and the restrictive factors, in this case, are the costs involved. Thus, the logistics service represents a balance between service priorities and costs (Bowersox and Closs, 2007).

In the description of Ballou's activities (2006), customer services cooperate with marketing to determine: the needs and wants of customers, the reactions of customers to the service, and the levels of customer services. Bowersox and Closs (2007), as well as Bowersox et al. (2014), highlight that the logistics service is measured in terms of availability (item available when required by the customer), operational performance (speed and consistency of delivery) and service reliability (quality of logistics).

Bowersox et al. (2014), separate the logistics operations in three areas, to better understand how the stock behaves along the supply chain: customer relationship management, responsible for aligning the links in the supply chain to provide product availability; manufacturing, is the area that manages the stock of products in process (stock in transit); and supply, is concerned with purchases and the movement and receipt of products and / or materials.

Thus, the classical literature comprehensively points out the direction towards a system of evaluation of logistics performance, highlighting the points of interest that strengthen the idea of a good logistics system.

Regarding the classic view of logistical performance assessment, it is worth noting that financial measures have been the basis used in measuring organizational performance, Otley (2008) and Grant (2013) agree that mainly in quantitative approaches. However, according to Grant (2013), companies are under the supervision of customers regarding non-financial and government measures on the issue of socio-environmental responsibility. Many of the performance managements at the operational level are based on specific performance indicators, which are generally not measured in financial terms.

However, at the highest levels, consideration of financial performance is inevitable, but the recognition that other important factors cannot be captured by financial measures has increased (Otley, 2008). According to Neely (2008), the question that operational managers want to answer from the measurement system is: "how efficient are we?". On the other hand, Corrêa (2014) defines performance measurement as the process of quantifying the result of actions.

Regarding logistical performance, in an older view, Caplice and Sheffi (1994) bring a systemic approach to measurements of logistical performance, dividing their view into three basic types of measurements: utilization, productivity and effectiveness. Usage measurements: are measurements that seek to demonstrate the rate of use of inputs; productivity measurements: measurements that seek to show the efficiency of the transformation of inputs into products; effectiveness measurements: measurements that show the quality of a result. 
Subsequently, Vivaldini and Pires (2010) define the performance of a logistics operator in relation to the competitive criteria of production: cost, quality, speed and flexibility. They present speed as the performance of deliveries, which according to the authors is usually measured in terms of the reliability of the promised deadlines and the duration of those deadlines. As for flexibility, the measures are in terms of the mix and volume of production. In addition, they point to cost as a basic competitive dimension and quality as a primary obligation.

The conceptions Caplice and Sheffi (1994) and Vivaldini and Pires (2010) end up converging to the conclusion of Bowersox et al. (2014), which focuses on the aspects of stock availability, operational performance, flexibility, and service reliability. According to Bowersox et al. (2014), the secret of logistical quality lies in the careful measurement of availability and operational performance.

\section{THE SYSTEMATIC LITERATURE REVIEW PROTOCOL}

This research followed guidelines adapted from the Systematic Literature Review (RSL), proposed by Tranfield et al. (2003), since it sought to establish peculiarities and parameters that corroborate the objective of this to map studies referring to the assessment of logistics performance. The research steps are described below.

- Prior review: the research was carried out with a previous review, in some articles on the topic, mainly from the Science Direct and Scopus database. Through this previous review, it was possible to identify some parameters and the inclusion and exclusion criteria to guide the research;

- Preparation of the research proposal: with the information gathered in the previous review, the research objectives were established. With the objectives defined, based on the previous review of the theme, research strings were established, that is, the keywords as shown in Table 1, which represents the research protocol;

- Development of the protocol: Based on the definition of the research question, the inclusion and exclusion criteria, also the parameters identified for the classification of the studies, the research protocol was configured. Which can be seen in Table 1;

- Obtaining publications: Gohr et al. (2013) present eight databases available on the web, for conducting research in production engineering. Among these, Scopus, Web of Science and Scielo were selected. In addition to the bases presented by Gohr et al. (2013), the search was extended to Science Direct, also relevant for research in production engineering. In this stage, searches were carried out on the referred bases with the selected keywords;

- Selection of articles: In this step, with the research protocol in hand, the titles and abstracts of the articles were first read, and, based on the inclusion and exclusion criteria, some of the articles were eliminated. Then, the selected articles were read in full, for data extraction, as well as exclusion for those who still presented criteria relevant to exclusion;

- Extraction of data from the studies: After selecting the articles, full reading was carried out, seeking to extract the information that answered the research questions regarding the classification parameters (Table 1);

- Data Synthesis: the data extracted in the previous step were consolidated into a table with all the information extracted, which served as a basis for the analysis of the results;

- Observation of the basic structure of construction of the evaluation systems: In this stage it was possible to identify basic elements in the proposed evaluation models, as well as the observation of scope gaps identified in the found models. For that, the research protocol information presented in Table 1 was analyzed.

When performing the RSL, to classify the articles, eleven parameters were considered to describe the general overview of the reviewed literature, in order to answer the questions described in Table 2 . The parameters are described below.

The parameters considered basic for the research were: Year, with the objective of identifying the evolution of the works developed over time (there was no time restriction); 
Country, aiming to identify those who develop more work on the theme; Object, with the objective of identifying the main objects studied in the research area, within the logistics sector; Objective, from which the main objective was extracted from the articles to identify what types of problems and / or questions the literature has been trying to solve.

Table 1 - Research Protocol

\begin{tabular}{|c|c|c|}
\hline \multicolumn{3}{|c|}{ Research Protocol } \\
\hline Keywords & \multicolumn{2}{|c|}{$\begin{array}{l}\text { Logistics performance indicators, logistics performance assessment, logistics } \\
\text { assessment, logistics key performance indicators, logistics indicators }\end{array}$} \\
\hline Boolean operator & \multicolumn{2}{|r|}{ OR } \\
\hline Data base & \multicolumn{2}{|c|}{ Science Direct, Web of Science, Scielo, Scopus } \\
\hline \multirow{2}{*}{ Inclusion Criteria } & \multicolumn{2}{|c|}{ - Portray logistic performance evaluation model } \\
\hline & \multicolumn{2}{|c|}{ - Use performance indicators in the logistics sector } \\
\hline \multirow{2}{*}{ Exclusion Criteria } & \multicolumn{2}{|c|}{ - Approach from the supply chain perspective, not just logistics } \\
\hline & \multicolumn{2}{|c|}{ - Portray the assessment of logistical performance in a national way } \\
\hline \multirow{6}{*}{ Parameters } & - Year & - Validation \\
\hline & - Country & - Based on Indicators \\
\hline & - objective & - Well-defined metrics \\
\hline & - Object & - Prioritization system \\
\hline & - Tools and Techniques used & - Main results \\
\hline & & - Search Suggestions \\
\hline Language & \multicolumn{2}{|r|}{ English } \\
\hline Types of Documents & \multicolumn{2}{|r|}{ Scientific articles } \\
\hline Years of Publication & \multicolumn{2}{|r|}{ No restrictions } \\
\hline
\end{tabular}

The methodological aspects observed in the articles studied were considered in the following group of parameters: Tools and Techniques used, from which the tools and techniques used in the research were identified, aiming at seeking a possible uniformity in the set of these tools used in the evaluation models; Validation, to identify how the articles validated their proposals. Thus, there was an answer to this parameter Literature Review (RL), Specialists (S) and Application (A).

Then, parameters were observed that indicated how the systems of evaluation of logistics performance discussed became effective: Based on indicators?, in which it was sought to identify if there are different evaluation models from the models based on indicators. In this context, the definition used for the indicator follows the provisions of Neely et al. (2008), who present the indicators as metrics used to quantify the efficiency and effectiveness of the actions. Thus, for this parameter, two answers were used, yes or no; Well-defined metrics? Considering that some articles do not show how to quantify the metrics of the indicators, this parameter sought to classify those that demonstrated and those that did not demonstrate these metrics. Having two possible answers, yes or no; Prioritization system? Parameter that sought to answer which articles have indicator prioritization (hierarchical) systems for indicator-based evaluation systems, thus considering three possible responses: yes, no or not applicable.

In the context of the conclusion of the research, the following parameters were observed: Main results, in which the main results obtained by the articles were highlighted, allowing the identification of a possible uniformity in the results; Research suggestion, where the suggestions for future research proposed by the authors were observed, since the area of assessment of logistical performance is a new subject, little explored and which opens up a range of study possibilities. 
The objectives that guided the elaboration of the research protocol aimed to find the answers to the questions gathered in Table 2 .

Table 2 - Questions to be answered with the analysis of the literature

What are the most researched objects in the assessment of logistics performance?

What are the most used tools and techniques in the construction of logistic performance evaluation models?

Which type of logistic performance evaluation model is predominant, based on indicators or other types?

Do Indicator-based models have well-defined metrics?

Do performance evaluation models have scales for prioritizing (ranking) indicators?

\section{RESULTS AND ASSOCIATED DISCUSSIONS}

In the first stage of the research, there was a previous review that was used to obtain an initial knowledge about the topic. In this beginning, the Scopus and Science Direct bases were used mainly, with the objective of identifying parameters and defining the inclusion and exclusion criteria, as mentioned in the previous section. Based on that, the research question was defined: "What is the current panorama of the literature and what are the main gaps regarding the assessment of logistics performance?", As well as the research protocol was consolidated.

The literature review was extended on the basis of Scopus, Web of Science, Scielo and Science Direct. After consulting the strings indicated in the protocol and excluding duplicate articles in the databases, the following article configuration was obtained: Scielo 2 articles, Web of Science 11 articles, Scopus 30 articles and, finally, Science Direct 96 articles, totaling 139 texts. As shown in Figure 1.

Following the steps of RSL, in the selection stage, from the reading of the titles and abstracts 38 articles were selected, which were read in full and only 13 of them were considered within the criteria of the research protocol. Of the 25 rejected articles, 5 of them were not available for consultation in full and were rejected for this reason.

\subsection{Main Research Objects in Literature}

To facilitate the interpretation of the research objects extracted from the articles, they were divided into three groups: Industry (objects referring to the manufacturing industry), P.S.L (Provider of Logistic Services) and others (other research objects). The main objects of study are companies that provide some type of logistical service, with 6 out of 13 articles presenting this type of study (see Table 3). This may be related to the fact that because they are logistics companies, the evaluation of their performance must be the logistical measurements and not because it is considered a strategic issue.

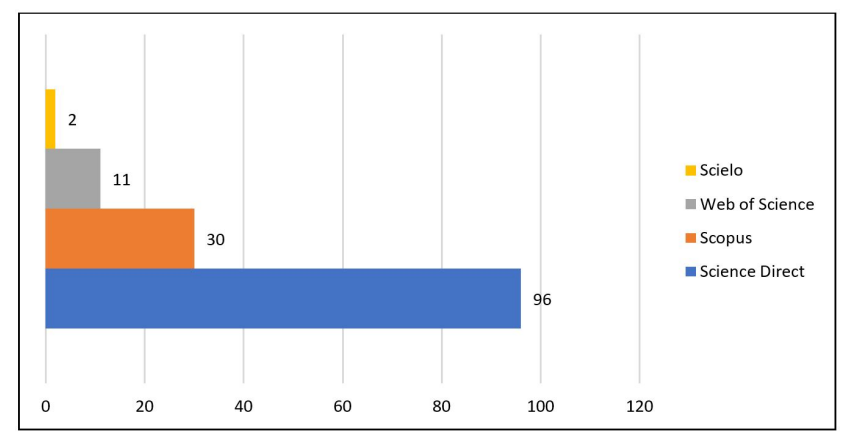

Figure 1 - Configuration of the Articles searched in the databases 
However, with regard to the work developed for industries in different sectors, logistics was considered within a more strategic issue. Since, it is not the main activity, but, there is a concern with the evaluation of the logistics performance, which can be strategic in the consolidation of the market and the reliability of the logistics services provided to customers. For example, there are works developed by Andersson et al. (1989) in the Swedish industry, Garcia et al. (2012) in the wine industry in Argentina and Guimarães and Salomon (2015) in the footwear industry in Brazil.

In addition to these, another 4 studies were developed in the health sector, Kritchanchai et al. (2018) in order to develop a strategy for the logistics processes developed in hospitals. Moons et al. (2019), have an approach from the perspective of internal logistics, more specifically in the supply network of internal materials of a hospital. Other areas were also explored, such as reverse logistics by Sangwan (2017) and humanitarian logistics by Larrea (2013). Despite all the relevance of logistics in today's world, it is observed that other areas need to be explored from the perspective of logistics performance.

\subsection{Tools and Techniques Used in Model Building}

The analysis of the tools and techniques used was divided into six groups: Literature review; Case study and observation; Surv-ey, Questionnaire and interviews; ANP (Analytic Network Process), BSC (Balanced Score Card) and Others. As shown in Figure 2 and Table 3.

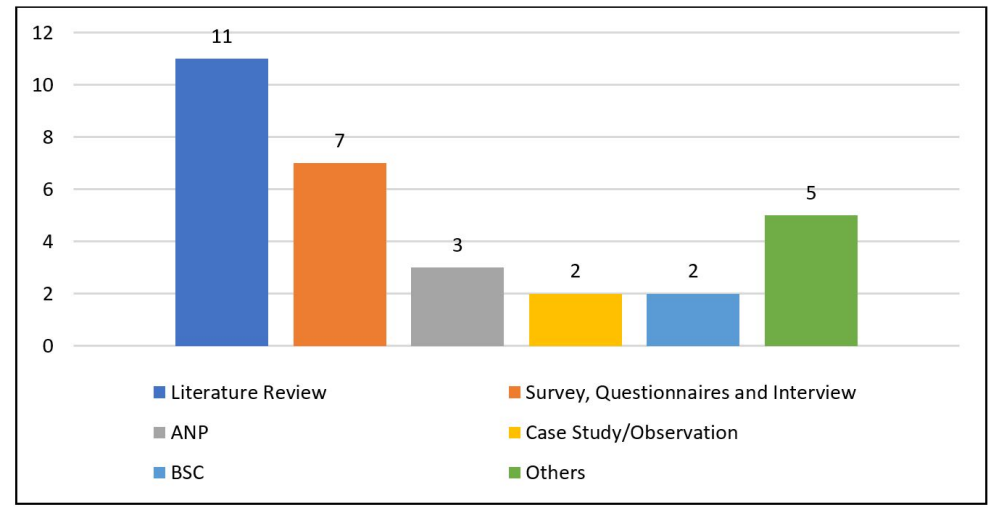

Figure 2 - Tools and Techniques used

\subsection{Based on Indicators or Hierarchization Systems?}

Regarding the analysis of the types of models for evaluating logistic performance prevalent in the proposals of the articles, the answer sought was related to the following question: "is the model based on indicators?". Thus, as a result of the analysis of the literature based on the 13 articles selected in the RSL, all presented the use of performance indicators. Of the 12 articles based on indicators only, 3 articles presented the metrics of the indicators used, Domingues et al., 2015; Garcia et al., 2012; and Larrea, 2013.

The use of indicators often leads to further actions to improve or maintain objectives. In some cases, due to resource constraints, it is necessary to prioritize some actions over others, some techniques already suggest a priority scale or hierarchy. For this reason, it was searched in the searched texts if the authors worked with prioritization (or scale of importance for the indicators). As a result, only 4 of the 12 articles surveyed are based on degrees of importance for the indicators. As shown in Figure 3, the results obtained in the literature showed that the main methods used in the hierarchy of the indicators are the models of multicriteria of decision (Garcia et al., 2012; Guimarães and Salomon, 2015; Kritchanchai et al., 2018; Kucukaltan et al., 2016). Among these methods, the ANP from English, Analytic Network Process translating freely, Analytical Network Process, was the most used, being considered in the works of Guimarães and Salomon (2015), Kritchanchai et al. (2018) and Kucukaltan et al. (2016). 
Table 3 - Tools used and form of validation

\begin{tabular}{|c|c|c|c|c|}
\hline Authors & Country & Object & $\begin{array}{c}\text { Tools and } \\
\text { techniques used }\end{array}$ & $\begin{array}{c}\text { Validati } \\
\text { on }\end{array}$ \\
\hline $\begin{array}{l}\text { Andersson et al. } \\
\text { (1989) }\end{array}$ & Sweden & $\begin{array}{l}\text { Swedish } \\
\text { Industry }\end{array}$ & $\begin{array}{c}\text { - Literature Review } \\
\text { / - Survey / } \\
\text { - Case Study }\end{array}$ & $\mathrm{RL}, \mathrm{S}, \mathrm{A}$ \\
\hline Garcia et al. (2012) & Argentina & Wine industry & $\begin{array}{c}\text { - Literature review } \\
\text { - Case study/ } \\
\text { Observation } \\
\text { - Questionnaires/ } \\
\text { interviews }\end{array}$ & $\mathrm{RL}, \mathrm{S}, \mathrm{A}$ \\
\hline Larrea (2013) & Colombia & $\begin{array}{l}\text { Humanitarian } \\
\text { Logistics }\end{array}$ & $\begin{array}{c}\text { - Literature Review } \\
\text { /- BSC }\end{array}$ & $\mathrm{RL}, \mathrm{A}$ \\
\hline Andrejic et al. (2013) & Serbia & $\begin{array}{l}\text { Distribution } \\
\text { centres }\end{array}$ & $\begin{array}{l}\text { - Literature review / } \\
\text { - PCA-DEA }\end{array}$ & $\mathrm{RL}, \mathrm{A}$ \\
\hline Wang et al. (2014) & China & $\begin{array}{l}\text { Chinese bulk } \\
\text { port }\end{array}$ & - Process Mining & A \\
\hline $\begin{array}{l}\text { Domingues et al. } \\
\qquad(2015)\end{array}$ & Portugal & $\begin{array}{l}\text { 3PL - Third- } \\
\text { Party Logistics } \\
\text { Provider }\end{array}$ & $\begin{array}{c}\text { - Literature Review } \\
\text { / - A list of } \\
\text { performance } \\
\text { indicators / - } \\
\text { Interviews }\end{array}$ & $\mathrm{RL}, \mathrm{S}$ \\
\hline $\begin{array}{l}\text { Guimarães e } \\
\text { Salomon (2015) }\end{array}$ & Brazil & $\begin{array}{l}\text { Footwear } \\
\text { industry }\end{array}$ & $\begin{array}{c}\text { - Survey / - ANP /- } \\
\text { Super / Decisions } \\
\text { software version } \\
2.0 .8\end{array}$ & $S$ \\
\hline Pereira et al. (2015) & Brazil & $3 P L$ & $\begin{array}{l}\text { - Literature Review } \\
\text { /- Questionnaire }\end{array}$ & $\mathrm{RL}, \mathrm{S}$ \\
\hline Silva et al. (2015) & Spain & Logistics & $\begin{array}{l}\text { - Literature Review- } \\
\text { Survey- Interviews }\end{array}$ & $\mathrm{RL}, \mathrm{S}$ \\
\hline $\begin{array}{l}\text { Kucukaltan et al. } \\
\qquad(2016)\end{array}$ & Turkey & $\begin{array}{l}\text { Turkish } \\
\text { logistics } \\
\text { industry }\end{array}$ & $\begin{array}{l}\text { - Literature Review } \\
\text { /- BSC /- ANP /- } \\
\text { Online survey /- A } \\
\text { list of performance } \\
\text { indicators }\end{array}$ & $\mathrm{RL}, \mathrm{S}, \mathrm{A}$ \\
\hline Sangwan (2017) & India & $\begin{array}{l}\text { Reverse } \\
\text { Logistics }\end{array}$ & - Literature Review & $\mathrm{RL}$ \\
\hline $\begin{array}{l}\text { Kritchanchai et al. } \\
\text { (2018) }\end{array}$ & $\begin{array}{l}\text { Laos/Malaysia /Myanmar/ } \\
\text { Singapore/ Thailand }\end{array}$ & Hospital & $\begin{array}{c}\text { - Literature Review } \\
\text { / - ANP / } \\
\text { - Questionnaires } \\
\text { /Interviews }\end{array}$ & $\mathrm{RL}, \mathrm{S}$ \\
\hline Moons et al. (2019) & Null & $\begin{array}{c}\text { The internal } \\
\text { hospital supply } \\
\text { chain }\end{array}$ & - Literature Review & $\mathrm{RL}$ \\
\hline
\end{tabular}

However, the hierarchical methods proposed by the authors are still very expensive, as they depend a lot on the use of software to make processes more agile. Thus, there is a need for a prioritization model that is more intuitive and that can encompass the organization's strategy.

\subsection{Main Results and Observed Performance Dimensions}

In general, it was observed (Table 4) that the results of each research are in fact the proposal of a set of indicators that support a performance evaluation (except Wang et al., 2014), showing that the intention was to generate an alternative for 
different contexts (objects studied discussed in section 4.1) because there are gaps in the literature. However, in most of the articles studied, the literature was the starting point in the construction of the proposed systems, sometimes as a source for the adoption of already proposed indicators, sometimes allowing the observation of proposed evaluation dimensions that could motivate the proposal of a new indicator. of performance.

The idea that performance indicators belong to different dimensions of analysis is also very present in the article base studied, only Wang et al. (2014) and Pereira et al. (2015) did not use this view. The different dimensions of performance analysis are implicit in the grouping of indicators used by the researchers, as noted in Table 5.

Table 4 - Main results in the articles studied

\begin{tabular}{|c|c|}
\hline Authors & Main results \\
\hline Andersson et al. (1989) & $\begin{array}{l}\text { We have combined the financial approach and the physical approach } \\
\text { with the help of a discussion in terms of "internal vs. external" } \\
\text { measures to illustrate the quantifiable aspects of the logistics system. }\end{array}$ \\
\hline Garcia et al. (2012) & $\begin{array}{l}\text { The contributions of this research include the definition and } \\
\text { representation of a model for the WSC, and a framework of KPI for } \\
\text { measuring logistics performance along the wine supply chain. }\end{array}$ \\
\hline Andrejic et al. (2013) & $\begin{array}{c}\text { Based on information obtained from the management company } \\
\text { second hypothesis is set. Namely, management assumption is that } \\
\text { DCs located in large cities are more efficient than DCs located in } \\
\text { small cities. }\end{array}$ \\
\hline Larrea (2013) & $\begin{array}{l}\text { - Key performance indicators can be used to measure the efficiency } \\
\text { of logistics management of humanitarian organizations working in } \\
\text { Colombia. }\end{array}$ \\
\hline Wang et al. (2014) & $\begin{array}{l}\text { As a result, it has been demonstrated that actual process executions } \\
\text { may significantly deviate from the designed processes, which } \\
\text { incorporate the standard operation procedures. As a result of these } \\
\text { process deviations important legal and operational risks may occur. }\end{array}$ \\
\hline Domingues et al. (2015) & $\begin{array}{l}\text { - A PMS framework with } 25 \text { performance indicators. } \\
\text { - A propose an individual KPI and PI record sheet where a more } \\
\text { detailed description and usage recommendations are presented. }\end{array}$ \\
\hline Silva et al. (2015) & $\begin{array}{c}\text { From the qualitative and quantitative analysis of the interviews, a set } \\
\text { of } 27 \text { performance indicators that can be used in governance of } \\
\text { logistics platforms was obtained. The indicators are contained in six } \\
\text { dimensions ... }\end{array}$ \\
\hline Guimarães e Salomon (2015) & $\begin{array}{l}\text { The results, presents the first four indicators (OC, RV, TI and ER) in the } \\
\text { same order of priority found as a sampling for Brazilian companies. } \\
\text { Which is justified by the influence of the related priority programs } \\
\text { (drivers), OC and RP with the Economic driver ( } 55.7 \%) \text {, and IT and ER } \\
\text { with Image driver ( } 24.6 \%) \text {, beyond the influence of other indicators. }\end{array}$ \\
\hline Pereira et al. (2015) & $\begin{array}{l}\text { - We note that the informants consider "freight fee" and "service } \\
\text { quality" to be the most relevant aspects when selecting a carrier. } \\
\text { - We note that "Relationship", "OTIF", "Quality", "Responsiveness", and } \\
\text { "Lead Time" are areas for improvement because they had lower } \\
\text { average scores among the evaluated indicators. }\end{array}$ \\
\hline Kucukaltan et al. (2016) & $\begin{array}{l}\text { - According to the results, the most important indicator is the } \\
\text { educated employee (15.61\%), followed by managerial skills }(14.78 \%) \text {, } \\
\text { cost }(13.50 \%) \text {, and profitability (10.36\%). Remarkably, these four } \\
\text { indicators account for more than a half of the total percentage of the } \\
15 \text { indicators (the most important in the logistic industry)... }\end{array}$ \\
\hline Sangwan (2017) & $\begin{array}{l}\text { This paper provides key activities, decision variables involved in each } \\
\text { activity and the key performance indicators required to take } \\
\text { informed decisions. }\end{array}$ \\
\hline
\end{tabular}


Table 4 - Continued...

\begin{tabular}{cc}
\hline Authors & Main results \\
\hline Kritchanchai et al. (2018) & $\begin{array}{c}\text { The study developed two logistics performance frameworks: national } \\
\text { and operational. At the national level, we adapted the HMN } \\
\text { framework for assessing the healthcare logistics performance. At the } \\
\text { operational level, we listed the logistics performance from literature } \\
\text { and interviews and used ANP to develop the set of KPIs to assess } \\
\text { operational performance. }\end{array}$ \\
Moons et al. (2019) & $\begin{array}{c}\text { From the literature, it can be summarized there are several objectives } \\
\text { and criteria for inventory and distribution management in hospitals. } \\
\text { However, a methodological approach is missing for selecting relevant } \\
\text { KPIs to measure the performance of the internal supply chain. }\end{array}$ \\
\hline
\end{tabular}

Understanding that the performance indicators must be assimilated as dimensional, or even grouped by similarities, is important to position them before the organizational strategy. According to Melnyk et al. (2014), it is necessary to develop methods that are aligned with the objectives of organizations, to measure logistical performance. These authors also state that measurement systems must be resilient, that is, they must be prepared for possible changes in the organization's strategies.

Table 5- Groupings in the proposed indicators

\begin{tabular}{|c|c|c|c|}
\hline Authors & 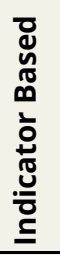 & :气 & Grouping of Indicators \\
\hline Andersson et al. (1989) & Y & $\mathrm{N}$ & $\begin{array}{l}\text { - Internal performance within the units / - External } \\
\text { performance between the different units in the company } \\
\text { / - External performance for the entire company towards } \\
\text { the customers / } \\
\text { - Supplier performance towards the company / - the } \\
\text { relation between the logistics performance and the } \\
\text { performance of the entire company }\end{array}$ \\
\hline Garcia et al. (2012) & $\mathrm{Y}$ & Y & $\begin{array}{c}\text { - Performance attributes (Quality, Timeliness, Logistics } \\
\text { Cost, Productivity and Capacity) / - Logistics processes } \\
\text { (Supply, Production and Bottling, Inventory Management, } \\
\text { Warehousing, Transportation and Distribution and } \\
\text { Customer Response) }\end{array}$ \\
\hline Andrejic et al. (2013) & Y & $\mathrm{N}$ & $\begin{array}{c}\text { - Equipment and capacity indicators / - Energy / - } \\
\text { Operational / - Utilization /- Quality }\end{array}$ \\
\hline Larrea (2013) & Y & Y & $\begin{array}{l}\text { - Appeal coverage /- Donations-to-Delivery Time / - } \\
\text { Financial Efficiency / - Assessment Accuracy }\end{array}$ \\
\hline Wang et al. (2014) & Y & $\mathrm{N}$ & Did not use the indicator approach \\
\hline Domingues et al. (2015) & $\mathrm{Y}$ & $\mathrm{Y}$ & - Strategic /- Tactical - Operational \\
\hline Silva et al. (2015) & $\mathrm{Y}$ & $\mathrm{N}$ & $\begin{array}{c}\text { - Financial / - Supplier /- Governance / - HR-Knowledge / - } \\
\text { Customer Service /- Sustainability }\end{array}$ \\
\hline Guimarães e Salomon (2015) & Y & $\mathrm{N}$ & $\begin{array}{l}\text { - Economic /- Image /- Citizenship /- Customer service /- } \\
\text { Legal }\end{array}$ \\
\hline Pereira et al. (2015) & Y & $\mathrm{N}$ & Did not use the clustering approach for the indicators \\
\hline Kucukaltan et al. (2016) & Y & $\mathrm{N}$ & $\begin{array}{c}\text { - Financial Perspective / - Learning and Growth } \\
\text { Perspective /- Internal Process Perspective /- Stakeholders } \\
\text { Perspective }\end{array}$ \\
\hline
\end{tabular}


Table 5 - Continued...

\begin{tabular}{|c|c|c|c|}
\hline Authors & 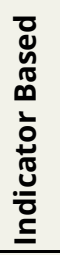 & 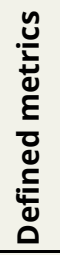 & Grouping of Indicators \\
\hline Sangwan (2017) & Y & $\mathrm{N}$ & - Collection / - Inspection and sorting /- Product recovery \\
\hline Kritchanchai et al. (2018) & Y & $\mathrm{N}$ & $\begin{array}{l}\text { - Commodity centralized purchasing and supply / - } \\
\text { Warehousing /- Inventory management /- Transportation } \\
\text { and distribution /- Delivery performance to customer } \\
\text { commit date /- Information technology management }\end{array}$ \\
\hline Moons et al. (2019) & Y & $\mathrm{N}$ & - Quality / - Time /- Financial /- Productivity \\
\hline
\end{tabular}

\subsection{Structure for the elaboration of a logistic performance evaluation system}

The articles included in this review show a common flow in the construction of their evaluation systems similar to each other. Based on these similarities and based on theoretical research, it was decided to adapt the methodology used in Yui et al. (2017), who identified the processes of a hospital pharmacy and translated it into a flowchart. This time, the common activities observed in the collected articles constituted a basic flow in the elaboration and implementation of a logistic performance evaluation system. This flow contains at least 6 and at most 7 activities: Literature review, Proposal of indicators and metrics, Interview with experts, Hierarchization / prioritization of indicators (may or may not occur), Application of metrics, Analysis of results and Action plan. And just as in Yui et al. (2017), these activities resulted in a flowchart, as shown in Figure 3.

The initial stage of building performance evaluation models consists of identifying in the literature a system with an application similar to the object of interest. In this case, it is important to observe the object of study in the scope of the research considered, in addition, operational or productive sector similarities are welcome, as they may allow simple adaptation. Of the authors surveyed, the only one who did not use this procedure was Wang et al. (2014).

After listing the indicators identified in the literature, the second stage is characterized by the selection of indicators and their metrics, considering the context of application of the system to be developed. First, this selection and proposal should be based only on the literature and observation of the object of interest and, subsequently, the experts' assessment may cause an adjustment in the initial proposal.

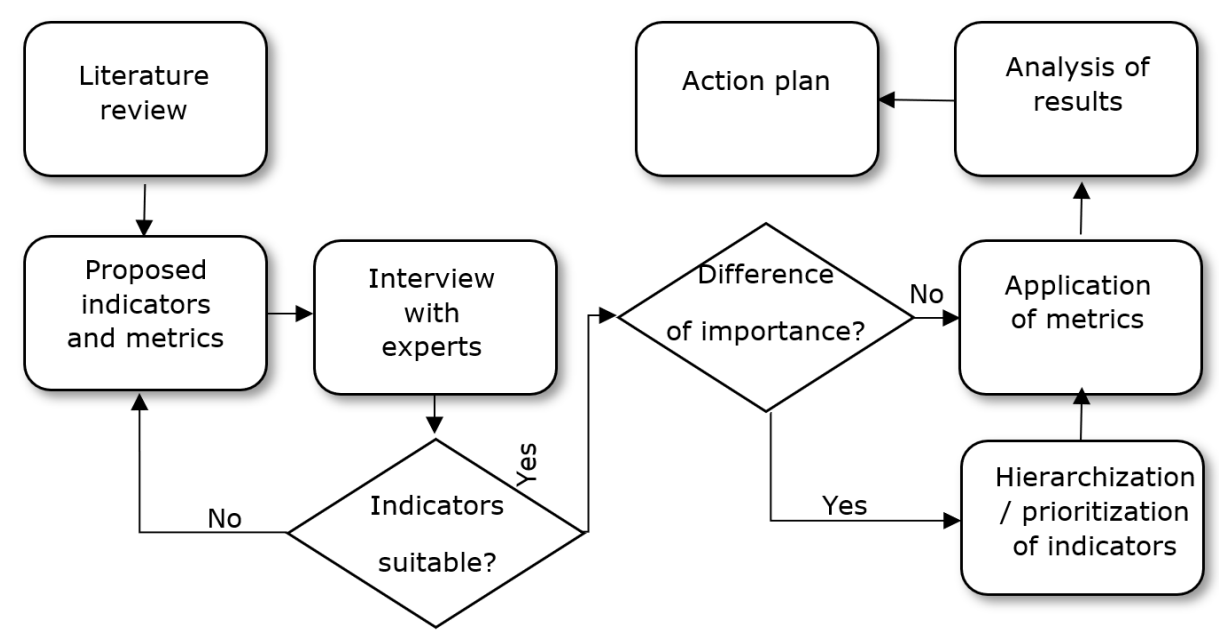

Figure 3 - Elaboration of a logistic performance evaluation system 
Domingues et al. (2015) and Kucukaltan et al. (2016) present, as a later step, an interview with specialists in the field of logistics, to validate the selected performance indicators. In this proposal, it is suggested that the specialists be composed of managers from sectors responsible for logistical activities, as well as managers involved with the company's corporate vision. The proposed indicators and metrics must be aligned with corporate goals, as in practice they must compose a larger system, including aligned with supply chain management.

A possible result obtained from the consultation with specialists is the need to relate a degree of importance to the proposed indicators and metrics, that is, to fit them in a prioritization or hierarchization system. The literature is vast on the techniques used for this purpose, in the reviewed articles, models based on decision criteria, commonly used in operational research, were used. However, it is worth mentioning that there are other proposals for prioritizing criteria that are easier and faster to apply.

One of the most widespread prioritization methods in the literature is the importanceperformance matrix method, first presented by Martilla and James (1977), later refined by Slack (1994) and presented by Slack et al. (2015). The importance-performance matrix seeks to associate the importance given by the customer with the performance offered by the organization, thus making it possible to prioritize efforts on indicators that are really important for customers, making the level of company service increases. Subsequently, the matrix can be used again to then check the next indicator to be prioritized.

Once the metrics are defined and their importance, the Metrics Application step is immediate, as long as the databases are properly available. In the sequence, there is the Analysis of the results, where the metrics compose the indicators, resulting in a performance score. The objective of consolidating the metrics is to create the basis for preparing the Action Plan, which generally brings together actions aimed at maintaining or improving performance.

\section{OPPORTUNITIES AND CHALLENGES IN THE DEVELOPMENT OF LOGISTICS PERFORMANCE SYSTEMS}

Throughout the execution of this research, it was possible to observe aspects that demarcate development opportunities for new research and applications in the theme, as well as the challenges related to these opportunities. The aspects that stood out and provoke reflection are:

- The interest in the theme (logistical performance assessment) has been presented globally and the studies go from the West to the East. The interest in the theme reflects the demand for evaluation systems that correspond to management needs. It is necessary to develop research in different application contexts, considering mainly regional conditions (relief, climate, economy, transport matrix, culture, etc.). A possible challenge concerns the basis for collecting data in an evaluation system, the information system, because in certain regions, the provision of services such as internet and cell phones may be unsatisfactory;

- It should be noted that the studies are more focused on the manufacturing industry and companies providing logistical services. It is opportune to develop logistic performance systems aimed at the growing service sector, the quality of service is influenced by logistic performance, often representing a competitive advantage. On the other hand, the customer interface of the service sector is larger than the interface of the manufacturing industry, which can make the task of collecting data for the adopted metrics expensive. In addition, the level of customer adherence to participate in this process may be low, as relations are quick and, at times, occasional;

- Reverse logistics was poorly contemplated, only one survey was found. Thus, the development of more research in the context of reverse logistics is yet another opportunity to contribute, mainly with the growing interest in sustainability and topics such as green logistics and sustainable logistics. Performance is often associated with economic aspects, reverse logistics still lacks an approach aimed at adding value and not just as a legally imposed penalty; 
- Decision processes often refer to the prioritization of actions due to resource constraints, however, only four studies were found that consider this approach and, therefore, the opportunity for proposals to define priorities or degrees of importance for indicators follows. The challenge arises mainly when these proposals are aimed at areas such as health and humanitarian logistics. In these cases, the very concepts of performance, efficiency and effectiveness (basis for the definition of indicators, metrics and prioritization) must be framed from another point of view, other than financial, as human lives are directly affected;

- Finally, the lack of discussion on the alignment between the assessment of logistical performance and the organization's own performance as a whole, or even with the performance of the chain, was also notorious. The opportunity arises to formalize the relationship between the company's performance conception as an integral part of a chain and its logistical activities. The challenge is present in the performance evaluation of supply chains, where the data generated at the interfaces of the different links, with regard to logistical activities, face problems such as the sharing of information and the very reliability of that information.

Thus, reflections on such aspects referred to a set of research and development opportunities, as well as their corresponding challenges, which are gathered in Table 6.

Table 6 - Challenges and opportunities in the development of evaluation systems

\begin{tabular}{|c|c|c|}
\hline Observed aspect & Opportunities & Challenges \\
\hline $\begin{array}{c}\text { Global interest in the theme of } \\
\text { logistics performance indicator } \\
\text { systems }\end{array}$ & $\begin{array}{l}\text { Develop research systems for } \\
\text { logistic performance indicators } \\
\text { in different regional contexts }\end{array}$ & $\begin{array}{c}\text { Peculiarities such as } \\
\text { transportation matrix, } \\
\text { telephony, internet etc. can } \\
\text { threaten the deployment of } \\
\text { these systems }\end{array}$ \\
\hline $\begin{array}{l}\text { Studies focused on the } \\
\text { manufacturing industry and } \\
\text { logistics operators }\end{array}$ & $\begin{array}{l}\text { Extend the proposed systems } \\
\text { of logistic performance } \\
\text { indicators for the service sector }\end{array}$ & $\begin{array}{l}\text { Difficulty in consolidating } \\
\text { logistics performance metrics } \\
\text { from data fed by customers }\end{array}$ \\
\hline $\begin{array}{c}\text { Only one proposal } \\
\text { contemplating reverse logistics }\end{array}$ & $\begin{array}{l}\text { Present proposals in different } \\
\text { chains, including considering } \\
\text { Green Logistics and Sustainable } \\
\text { Logistics concepts }\end{array}$ & $\begin{array}{c}\text { Propose indicators and metrics } \\
\text { in the environmental and social } \\
\text { context to contemplate } \\
\text { sustainability }\end{array}$ \\
\hline $\begin{array}{c}\text { Few studies consider } \\
\text { prioritizing performance } \\
\text { indicators }\end{array}$ & Consider hierarchical methods & $\begin{array}{l}\text { In areas such as health and } \\
\text { humanitarian logistics, the } \\
\text { concepts of performance, } \\
\text { indicators and their metrics } \\
\text { must be rethought }\end{array}$ \\
\hline $\begin{array}{c}\text { Lack of alignment of the } \\
\text { logistics performance system } \\
\text { with the corporate and chain } \\
\text { views }\end{array}$ & $\begin{array}{c}\text { Theorize about the interface of } \\
\text { the organization's corporate } \\
\text { vision of performance, } \\
\text { including in the context of the } \\
\text { chain }\end{array}$ & $\begin{array}{l}\text { Achieve information sharing } \\
\text { within and between companies } \\
\text { that reliably feeds the system }\end{array}$ \\
\hline
\end{tabular}

\section{FINAL CONSIDERATIONS}

It was observed that there is no concentration of research in just one region, the works found were published in several regions. Thus, it is concluded that despite the reduced number of researches developed, the relevance given to the theme is global. In addition, the objects of study of these surveys are diverse, not only in logistics companies, but also in several other organizations.

An important contribution of this research was the proposed flow for the construction of a logistic performance evaluation system. Bibliographic research has shown that studies are 
still scarce, so the proposed structure (Figure 3) may represent an important initial reference in the process of implementing such a system in different organizations.

The validation of the indicators or models used in the assessment of logistical performance has been an important aspect in research. The analysis showed that 6 (six) articles out of 13 (thirteen) validated the proposed models with practical applications. However, most of the proposals studied were validated through a literature review, probably due to the speed and low complexity of this process, since researchers depend only on the database.

The main limitation of this research can summarize the number of bases researched and the lack of full access in the case of some research. Therefore, a search including other bases may bring in some new element, but without compromising the here related findings.

The low evolution in the number of publications per year was notable, showing that this is still a little explored and under development topic. This research focused on the assessment of logistics performance in the context of business logistics, a suggestion for the development of future works would be to expand the search for works focused on Supply Chain Management (SCM). In addition, conducting a study on other bases for comparative purposes would also be another relevant suggestion.

\section{REFERENCES}

Andersson, P., Aronsson, H. and Storhagen, N.G. (1989), "Measuring logistics performance", Engineering Costs and Production Economics, Vol. 17, No. 1-4, pp. 253-62.

Andrejić, M., Bojović, N. and Kilibarda, M. (2013), "Benchmarking distribution centres using Principal Component Analysis and Data Envelopment Analysis: a case study of Serbia", Expert Systems with Applications, Vol. 40, No. 10, pp. 3926-33.

Arbache, F.S., Moreira, C. and Salles, W.F. (2011), Gestão de Logística, Distribuição e Trade Marketing, 4th ed., Editora FGV, Rio de Janeiro.

Ballou, R.H. (2006), Gerenciamento da Cadeia de Suprimento: Logística Empresarial, 5th ed., Bookman, Porto Alegre.

Bowersox, D.J. and Closs, D.J. (2007), Logística Empresarial: o Processo de Integração da Cadeia de Suprimento, 1st ed., Editora Atlas S.A., São Paulo.

Bowersox, D.J., Closs, D.J. and Cooper, M.B. (2014), Gestão Logística da Cadeia de Suprimento, 4. ed., AMGH, Porto Alegre.

Caplice, C. and Sheffi, Y. (1994), "A review and evaluation of logistics metrics", International Journal of Logistics Management, Vol. 5, No. 2, pp. 11-28.

Chopra, S. and Meindl, P. (2016). Supply Chain Management: Strategy, Planning, and Operation, 6th ed., Pearson, New York.

Corrêa, H.L. (2014), Administração de Cadeia deSuprimento e Logísitica: O Essencial, Editora Atlas S.A., São Paulo.

Council of Logistics Management (1998), Careers in Logistics, Oak Brook.

Domingues, M.L., Reis, V. and Macário, R. (2015), "A comprehensive framework for measuring performance in a third-party logistics provider", Transportation Research Procedia, Vol. 10, pp. 662-72.

Franco-Santos, M., Lucianetti, L. and Bourne, M. (2012), "Contemporary performance measurement systems: a review of their consequences and a framework for research", Management Accounting Research, Vol. 23, No. 2, pp. 79-119.

Fundação Dom Cabral (2018), Custo logístico tem um aumento de cerca de 15,5 bilhões da receita das empresas entre 2015 e 2017, São Paulo.

Garcia, F.A.E.A., Marchetta, M.G., Camargo, M. et al. (2012), "A framework for measuring logistics performance in the wine industry", International Journal of Production Economics, Vol. 135, No. 1, pp. 284-98.

Gohr, C.F., Santos, L.C., Gonçalves, A.M.C. et al. (2013), “Um método para revisão sistemática da literatura em pesquisas de engenharia de produção", in XXXIII Encontro Nacional de Engenharia de Produção, Salvador. 
Grant, D.B. (2013), Gestão de Logística e Cadeia de Suprimentos, 1. ed., Saraiva, São Paulo.

Guimarães, J.L.S. and Salomon, V.A.P. (2015), "ANP applied to the evaluation of performance indicators of reverse logistics in footwear industry", Procedia Computer Science, Vol. 55, pp. 139-48.

Kritchanchai, D., Hoeur, S. and Engelseth, P. Develop a strategy for improving healthcare logistics performance. Supply Chain Forum: An International Journal., p. 55-69, 2018.

Kucukaltan, B., Irani, Z. and Aktas, E. (2016), "A decision support model for identification and prioritization of key performance indicators in the logistics industry", Computers in Human Behavior, Vol. 65, pp. 346-58.

Larrea, O. (2013), "Key performance indicators in humanitarian logistics in Colombia", IFAC Proceedings Volumes, Vol. 46, No. 24, pp. 211-6.

Martilla, J.A. and James, J.C. (1977), "Importance-performance analysis", Journal of Marketing, Vol. 41, No. 1, pp. 77-9.

Melnyk, S.A., Bititci, U., Platts, K. et al. (2014), "Is performance measurement and management fit for the future", Management Accounting Research, Vol. 25, No. 2, pp. 173-86.

Moons, K., Waeyenbergh, G. and Pintelon, L. (2019), "Measuring the logistics performance of internal hospital supply chains: a literature study", Omega, Vol. 82, pp. 205-17.

Neely, A. (2008), "Measuring performance: the operations management perspective", in Neely, A. (Ed.), Business Performance Measurement: Unifying Teory and Integrating Pratictice, 2nd ed., Cambridge University Press, New York, cap. 3, pp. 64-81.

Otley, D. (2008), "Accounting performance measurement: a review of its purposes and practices", in Neely, A. (Ed.), Business Performance Measurement: Unifying Teory and Integrating Practice, 2nd ed., Cambridge University Press, New York, cap. 1, pp. 11-35.

Pereira, D.E.A., Vieira, J.G.V., Silva, J.E.A.R. et al. (2015), "Assessing carriers' logistical performance indicator by shippers in the São Paulo Metropolitan Area", Journal of Transport Literature, Vol. 9, No. 4, pp. 30-4.

Reis, A.C., Souza, C.G., Costa, N.N. et al. (2017), "Warehouse design: a systematic literature review", Brazilian Journal of Operations \& Production Management, Vol. 14, No. 4, pp. 542-55.

Sangwan, K.S. (2017), "Key activities, decision variables and performance indicators of reverse logistics", Procedia CIRP, Vol. 61, pp. 257-62.

Silva, R.M.D.E.A., Senna, E.T.P., Lima Júnior, O.F. et al. (2015), "A framework of performance indicators used in the governance of logistics platforms: the multiple-case study", Journal of Transport Literature, Vol. 9, No. 1, pp. 5-9.

Slack, N. (1994), "The importance-performance matrix as a determinant of improvement priority", International Journal of Operations \& Production Management, Vol. 14, No. 5, pp. 59-75.

Slack, N., Chambers, S. and Johnston, R. (2015), Administração da Produção, 4. ed., Atlas, São Paulo.

Tranfield, D., Denyer, D. and Smart, P. (2003), "Towards a methodology for developing evidence-informed management knowledge by means of systematic review", British Journal of Management, Vol. 14, No. 3, pp. 207-22.

Vivaldini, M. and Pires, S.R.I. (2010), Operadores Logísticos: Integrando Operações em Cadeia de Suprimentos, 1. ed., Editora Atlas S.A., São Paulo.

Wang, Y.E.A., Caron, F., Vanthienen, J. et al. (2014), "Acquiring logistics process intelligence: Methodology and an application for a Chinese bulk port", Expert Systems with Applications, Vol. 41, No. 1, pp. 195-209.

World Bank Group (2018), "Global Rankings 2018", available at: https://lpi.worldbank.org/international/global/ (accessed 10 May 2019).

Yui, K.P., Reis, C.C.C., Moro, M.F. et al. (2017), "Parameters involved in the internal reverse logistics of a hospital pharmacy", Brazilian Journal of Operations \& Production Management, Vol. 14, No. 3, pp. 318-26.

Authors contribution: All authors contributed equally to this research. 